\title{
On The Problems and Strategies of Multimedia Technology in English Teaching
}

\author{
Jun Xu \\ Department of Foreign Language, Dezhou University, Dezhou, China \\ Email: xujun56cn@yahoo.com.cn
}

\begin{abstract}
The rapid rising and development of Information Technology offered a better pattern to explore the new teaching model. As a result, multimedia technology plays an important role in English teaching. However, some teachers rely so much on the technology that the disadvantage emerges in the teaching process. In order to make more efficient use of the technology and the practical value in English teaching, the paper put forward positive suggestion and strategy by analyzing the problems in the use of multimedia technology.
\end{abstract}

Index Terms - multimedia technology, English teaching, problem and strategy

\section{INTRODUCTION}

21 st century is the age of globalization that one important instrument is to grasp one or various foreign languages and English language comes first. With the rapid development of science and technology, the emerging and developing of multimedia technology and its application to teaching, traditional teaching model is unfit for contemporary English teaching and therefore multimedia technology featuring audio, visual, animation effects comes into full play in English class teaching and sets a favorable platform for reform and exploration on English teaching model in the new era. It's proved that multimedia technology plays a positive role in promoting activities and initiatives of student and teaching effect in English class.

\section{ANALYSIS ON NECESSITY OF APPLICATION OF MULTIMEDIA TECHNOLOGY TO ENGLISH TEACHING}

\section{A. To Cultivate Students' Interest in Study}

Nowadays, the stereotyped traditional teaching methods and environment are unpopular while multimedia technology featuring audio, visual, animation effects naturally and humanely makes us more access to information. Besides, with such characteristics as abundant-information and crossing time and space, multimedia technology offers a sense of reality and functions very well, which greatly cultivates students' interest and motivation in study and their involvement in class activities.

\section{B. To Promote Students' Communication Capacity}

Traditional teaching has trivializes the students' capacity to comprehend certain a language and hampers their understanding to structure, meaning and function of the language, and makes the students passive recipients of knowledge. So it is hard to achieve the target of communication. With teachers' instructions leading students' thought patterns and motivating students' emotions, the multimedia technology class set in new-type internet classroom seeks integration of teaching and learning and provides the students greater incentives. The PPT courseware in university English teaching can activate students' thinking; the visual and vivid courseware transforms English learning into capacity cultivation. And such in-class activities as group discussion, subject discussion, and debates can also offer more opportunities for communication among students and between teachers and students. So multimedia technology teaching has uniquely inspired students' positive thinking and communication skills in social practice.

\section{To Widen Students' Knowledge to Gain an Insightful Understanding to Western Culture.}

The multimedia disc courseware can offer the students abundant information; the output of multimedia comprehensive English disc is far more plentiful than textbooks, and it displays vivid cultural background, rich content and true-to-life language materials, which are much natural and closer to life. Not only could learners improve their listening ability, but also learn the western culture. Grasping information through various channels can equip the students with knowledge and bring about information-sharing among students and make them actively participate in class discussion and communication. Integration of human-machine communication and interpersonal communication leads to overall development of students' listening, speaking, reading and writing.

\section{To Improve Teaching Effect}

Multimedia teaching enriches teaching content and makes the best of class time and breaks the "teacher-centered" teaching pattern and fundamentally improves class efficiency. It is very common that the university students have their 
English classes in very large yet crowded classrooms. Under such circumstances, it is difficult for the students to have speaking communication. The utilization of multi-media sound lab materializes the individualized and co-operative teaching.

The traditional teaching model mainly emphasized on teachers' instruction, and the information provided was limited. On the contrary, multimedia technology goes beyond time and space, creates more vivid, visual, authentic environment for English learning, stimulates students' initiatives and economizes class time meanwhile increases class information.

\section{ANALysis ON PROBlems ARISING FROM APPLICATION OF MUltimediA TECHNOLOGY to ENGLISH TEACHING}

In spite of advantages of application of multimedia technology to English class teaching as to improve teaching effect and university students' overall capacities, there are many problems existing in practical teaching, such as:

\section{A. Major Means Replaced by the Assisting One.}

Application of multimedia technology is an assisting instrument to achieve the projected teaching effect. While, if totally dependent on multimedia devices during teaching, the teachers may be turned into slaves to the multimedia and can not play the leading role in teaching. It is observed in practice that a lot of teachers are active in multimedia technology application so that they are much engaged in searching information and working out courseware. In class, they are standing by the computer and students are fixing their attention only on the screen, and therefore, there is no eye contact between teachers and students. CAT has played a dominant role in class, while both teachers and students are enslaved by the computer, and students' initiatives, originality, teachers' individualized art in teaching are totally restricted and erased. The trend of modern information and technology teaching appears to the extremity regardless of the essence of the traditional teaching. And hence, the notion of Creative Education should be fully comprehended that modern educational techniques serves an assisting instrument rather than a target; and that should not dominate class. With the assistance of computer in teaching, teachers are supposed to fully utilize the academic syllabus and teaching material, to find our how much knowledge the students have gained. The multimedia information should be less and better adopted with striking emphasis and breakthroughs in teaching.

\section{B. Loss of Speaking Communication}

For a time, it has been proposed that English class should be carried through all in English language. English language and English analysis by the teachers are effective in conveying knowledge to the students from English pronunciation to comprehension, improving students' English thought patterns and oral expression. Whereas, the introduction of multimedia technology featuring audio, visual, textual effect can fully meets audio and visual requirements of the students and enhance their interest, but it also results in lack of communication between teachers and students, replacement of teachers' voice by computer sound, and teachers' analysis by visual image and students' few chances for speaking communication. With the favorable atmosphere by the mutual communication between teachers and students fading away, and sound and image of multimedia affecting students' initiative to think and speak, English class turns to courseware show and students are made viewers rather than the participants of class activities.

\section{The Shrinking of Students' Thinking Potential}

It is clear that language teaching is different from science subjects, for language teaching does not require demonstration by various steps, rather, the tense and orderly atmosphere is formed through questions and answers between teachers and students. Teachers raise impromptu and real-time questions and guide the students to think, cultivate their capacity to discover and solve problems. However, due to over-demonstration and pre-arranged order, the courseware lacks real-time effect and cannot feedback students' study so it ignores emphasis and importance in teaching; it also neglects instruction in students' thinking and appreciation to the beauty of language; furthermore it paid little heed to free learning atmosphere and the notion-"happy leaning". It is plain that multimedia plays a positive role in stimulating students' thinking, inspiring their paths of thinking, strengthening their capacities of discovering, contemplating and solving problems. In this way, it should be noted that cultivation of students' thinking capacity should be the major objective in teaching and multimedia not take up the students' time for thinking, analyzing and exploring questions.

\section{Abstract Thinking Replaced by Imaginal Thinking}

The process of cognition goes through perceptual stage and rational stage. It also applies to studying process. It is our hope that teaching makes students adopt the outlook cognition from perceptual recognition to rational apprehension, and greatly leap from perceptual thinking to rational thinking. Therefore, it is the major objective in teaching to enhance the students' abstract thinking. The multimedia technology makes content easier, and with its unique advantages, it can clarify the emphasis in teaching. While if the image and imagination in students' mind were merely showed on the screen, their abstract thinking would be restricted and logical thinking would waste away. At present the decreased students' reading competence has become a major concern for reason that textual words are replaced by sound and image, handwriting by keyboard input. The over-application of multimedia technology would worsen the situation.

All in all, the multimedia as an assisting instrument, can not replace the dominant role of teachers and it is part of a complete teaching process. Besides, it is not a mechanic imitation of teaching, rather it integrates the visual, textual 
demonstration with teachers' experiences to contribute to the programmed, automatic and continuous teaching project so as to enhance the overall improvement of students' listening, speaking, reading and writing.

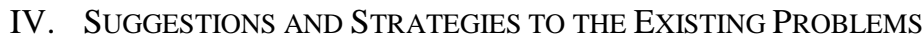

In practical teaching, it is improper to duplicate the textual material simply to the screen so that the teacher's position is ignored. In order to ensure the function of multimedia in teaching, it should be noted that:

\section{A. The Beauty of Courseware Is not the Sole Pursuit}

It is proved through practice that adequate application of multimedia technology to teaching can make breakthroughs in class teaching. That is to say, during multimedia assisting teaching, teachers still play the leading role that their position could never be replaced by the computer. For instance, the introduction to each lesson and speaking communication are good way to improve students' listening and speaking which the computer cannot fulfill. Therefore, teachers' interpretation shall not be overlooked. Meanwhile, as a practical linguistic science, English should be used very often in class to cultivate the students' communicative competence. Multimedia, as an instrument for assisting teaching, serves the teachers despite its extraordinary effect. So teaching determines whether to adopt multimedia technology. Otherwise, the teachers were acting as the projectionist, clicking the screen.

\section{B. The Computer Screen can't Substitute the Blackboard.}

Some teachers take the computer screen as the blackboard. They have input exercises, questions, answers and teaching plans into the computer and display them piece by piece, without taking down anything on the blackboard or even the title of a lesson. It is known that teachers are supposed to simulate situations based on teaching and guide the students to communicate in English. Besides, traditional writing on blackboard is concise and teachers can make adjustment and amendment to it if necessary. Furthermore, experienced teachers know well that a perfect courseware is an ideal project in mind, and that in practice, they need to enrich the content on the blackboard with emerging of new questions raised by the students.

\section{PowerPoint can not Take the Place of Student's Thinking and Practices}

At present, most multimedia courseware mainly features on image and animation of teaching materials in order to cause audio and visual effect, which lively displays the content of textual materials and helps the students deeply understand the texts. A problem remains that displaying of the content of texts in the PPT courseware cannot take the place of students' thinking or English communication in simulated circumstance. When working on and utilizing the courseware, we need to encourage the students to use their own mind and speak more, actively join in class practice; we should not overuse the courseware merely in the hope of adding the modernized feature to class teaching

\section{Traditional Teaching Instruments and Devices should not be Overlooked.}

The function of multimedia assisting in teaching cannot be replaced by many other instruments, which does not mean that multimedia can replace any other form of instrument. Some teachers tend to entirely depend on multimedia teaching. While, it should be noticed that although multimedia has its unique advantages in teaching, the characteristic functions of other forms of teaching instruments are still incomparable. For example, the recorder still plays a role in broadcasting listening material. So teachers are supposed to choose appropriate media and instrument based on the requirements of teaching and integrate multimedia instrument with traditional one and fully perform their merits, rather than merely in pursuit of trendy method.

\section{E. Multimedia Technology should not be Overused.}

Some teachers may possess the improper concept that they would totally apply multimedia technology in their teaching. It is also believed that the more utilization of multimedia technology, the better class atmosphere may grow, the more actively the students get involved in class participation, the more easily the material access to the students. Apparently, the students show some interest in leaning, but actually, they feel like looking on. In practice, the more unconscious attention the students pay, the more interference of teaching information during transmission, the less the students take from the language materials. It is impossible to effectively train the students' language expression in class time.

It is clear that in spite of advantages of application of multimedia technology, it assists in teaching. During practical teaching, it is part of a complete teaching procedure. In practice, if multimedia technology would be properly implemented in English teaching, the students could make full use of English speaking and listening materials and develop their overall capacities, which is the objective for us to introduce multimedia technology to modern teaching. Thus, this leads to systematic training on students' listening, speaking, reading and writing, makes teachers' instructions come into great play, helps the student gain basic knowledge as well as language training at class, improves their expression ability in English and lays a fundamental basis for their English communication.

\section{REFERENCES}


[1] Limengtao.( 2001). Preliminary exploration of English classroom teaching by the multimedia projection. Foreign Language Circle, 3.

[2] Hejunlin,wangyaxiong, liuxueqing.( 2005). The existing problems of the multimedia teaching and the improving strategies. Exploration of Medicine Education, 4.

[3] Dengzhongyi.( 2005).The advantages and existing problems of the multimedia technology in the college experiment teaching and the settling strategies. Modern education technology, 5.

[4] Jiaoling.( 2003). The features, the principles and the methods of the multimedia teaching. The Academic Journal of National Academy of Guizhou, 3.

[5] Weidanhua. (2003).The application of the multimedia in the college English classroom teaching. Chinese geology Education, 2.

[6] Zhanghongling.( 2000). The development tendency of the modern foreign language teaching and the computer assisted instruction. Computer-Assisted Foreign Language Education, 3.

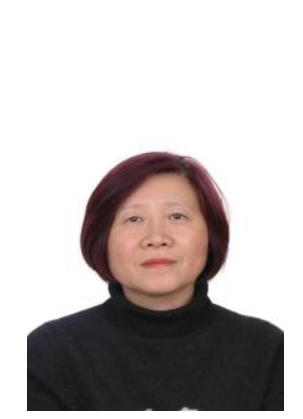

Jun Xu was born in Binzhou, China in 1956. She majored in English Linguistics and Literature in the department of Foreign Studies, Liaocheng University, China in 1976-1979 and completed equivalent M.A. degree courses on English Linguistics and Literature in Shandong University, Jinan, China in 2002. Supported by Chinese State-funded students studying abroad Project, she was a full-time Visiting Scholar in School of English Study, Nottingham University, UK in 2002-2003.

She is currently an associate professor and the Director of the School of Foreign Languages, Dezhou University, Shandong, China. She has written "Study on analysis of Students' Speaking Error and PETS-Instruction of Students' Speaking Error Analysis in English Speaking Teaching”, Vladivostock, Russia: Intelligent Potential of Advanced Education-Development of Russian Far East and Asia-Pacific Development, 2009; "Experiencing in Glamorous Language World", Yantai, China: Journal of Yantai Education Institute, 2004; "Backwash Effect on Current High School English Teaching in light of NMET", Shandong Enterprise Education, 2007; Translation works: The Cambridge Illustrated History of British Theatre', Shandong Pictorial Press. 2006. Her research interests include cross-cultural communication and English language teaching.

$\mathrm{Ms} \mathrm{Xu}$ is the Director of English Language Institute of Shandong Province. Her publications as "Antidotes to Computer Virus" was awarded the third prize by the $8^{\text {th }}$ Dezhou Municipal Excellent Social Scientific Achievements in 1995; "Influence of English and American Language and Culture on Chinese Language" was awarded the third prize by the $9^{\text {th }}$ Dezhou Municipal Excellent Social Scientific Achievements in 1996; "Basic Exploration on Fast-reading Teaching" was awarded the third prize by the $17^{\text {th }}$ Dezhou Municipal Excellent Social Scientific Achievements in 2004. 